\title{
miR-342 is associated with estrogen receptor- $\alpha$ expression and response to tamoxifen in breast cancer
}

\author{
YUE-JUN HE ${ }^{1,5}$, JIAN-ZHONG WU ${ }^{2}$, MING-HUA JI ${ }^{3}$, TAO MA ${ }^{4}$, EN-QI QIAO ${ }^{4}$, \\ RONG MA ${ }^{2}$ and JIN-HAI TANG ${ }^{5}$ \\ ${ }^{1}$ Surgery Department, The Second Affiliated Hospital of Xuzhou Medical College, Xuzhou, Jiangsu 221000; \\ ${ }^{2}$ Center Laboratory; ${ }^{3}$ Radiotherapy Department, Jiangsu Cancer Hospital, Nanjing, Jiangsu 210000; \\ ${ }^{4}$ Oncology Department of Nanjing Medical University, Nanjing, Jiangsu 210000; ${ }^{5}$ Breast Surgery, \\ Jiangsu Cancer Hospital, Nanjing, Jiangsu 210000, P.R. China
}

Received November 26, 2012; Accepted January 10, 2013

DOI: 10.3892/etm.2013.915

\begin{abstract}
Estrogen receptor- $\alpha(E R \alpha)$ is essential for estrogen-dependent growth and its level of expression is a crucial determinant of response to endocrine therapy and prognosis in ER $\alpha$-positive breast cancer. Breast cancer patients show a wide range of ER $\alpha$ expression levels which change in individual patients during disease progression and in response to systemic therapies. However, little is known concerning how the expression of $\mathrm{ER} \alpha$ is regulated in human breast cancer. Recently, several microRNAs (miRNAs) have been identified to regulate ER $\alpha$ expression and to predict ER, progesterone receptor (PR) and human epidermal growth factor 2 (HER2) status. The expression levels of miR-342 and ER $\alpha$ mRNA were analyzed in human breast cancer samples and cell lines by quantitative reverse transcription (RT)-PCR analysis. The correlations between the expression levels of miR-342 and clinicopathological factors were analyzed. Statistically significant associations were observed between miR-342 and ER, HER2 and vascular endothelial growth factor (VEGF) status in the human breast cancer samples and the levels of miR-342 gradually increased as ER $\alpha$ mRNA expression increased. Moreover, ectopic overexpression of miR-342 upregulated the expression levels of the ER $\alpha$ mRNA and significantly sensitized the MCF-7 cells to tamoxifen-induced apoptosis and inhibition of cellular proliferation. These results suggested that miR-342 expression is positively correlated with ER $\alpha$ mRNA expression in human breast cancer and that it may be a significant marker for predicting tamoxifen sensitivity in ER $\alpha$-positive breast cancer and a potential target for restoring ER $\alpha$ expression and responding to antiestrogen therapy.
\end{abstract}

Correspondence to: Professor J.H. Tang, Department of Breast Surgery, Jiangsu Cancer Hospital, No. 42 Baiziting, Nanjing, Jiangsu 210000, P.R. China

E-mail: 1294978898@qq.com

Key words: breast cancer, miR-342, estrogen receptor- $\alpha$, tamoxifen

\section{Introduction}

Breast cancer is the most common malignancy in females, accounting for $31 \%$ of all female cancers. Approximately two-thirds of breast cancers exhibit high concentrations of estrogen receptor (ER). The selective ER $\alpha$ modulator tamoxifen is the most commonly prescribed endocrine therapy. A 5 -year treatment of adjuvant tamoxifen therapy has been shown to reduce the 15 -year risk for recurrence and mortality in breast cancer patients with ER $\alpha$-positive cancer (1). However, adjuvant tamoxifen therapy fails in $30-40 \%$ of patients and nearly all patients with metastatic disease develop tamoxifen resistance. ER $\alpha$ is essential for estrogen-dependent growth and its level of expression is a crucial determinant of the response to endocrine therapy and the prognosis in ER $\alpha$-positive breast cancer $(2,3)$. There is no doubt that the more ER $\alpha$ is present in the tumor cells, the greater the likelihood of a favorable response to endocrine therapy (4), but little is known about how the expression of ER $\alpha$ is regulated in human breast cancer.

MicroRNAs (miRNAs) are small ( 21 nucleotides), noncoding RNAs that negatively regulate target genes by predominantly binding to the $3^{\prime}$ untranslated region ( $\left.3^{\prime} \mathrm{UTR}\right)$ of target mRNA, resulting in either mRNA degradation or translational repression (5). Evidence has shown that miRNA mutations or misexpression are associated with various types of human cancer and indicates that miRNAs are able to function as tumor suppressors and oncogenes (6). Previously, studies have shown that microRNA expression profiling also revealed that miRNAs are differently expressed among the molecular subtypes of breast cancer $(7,8)$.

Kondo et al reported that miR-206 was markedly decreased in ER $\alpha$-positive human breast cancer tissues and that the introduction of miR-206 into estrogen-dependent MCF-7 breast cancer cells led to the suppression of ER $\alpha$ expression and growth inhibition (9). Adams et al identified that miR-206 decreases endogenous ER $\alpha$ mRNA and protein levels in MCF-7 cells by acting through two specific miR-206 target sites within the 3'UTR of the human ER $\alpha$ transcript (10). Leivonen et al previously reported that five ER $\alpha$-regulating miRNAs, miR-18a, miR-18b, miR-193b, miR-302c and miR-206, directly targeted ER $\alpha$ in 3'UTR reporter assays (11). 
Furthermore, other studies demonstrated that miR-22 $(12,13)$ and miR-221/222 $(14,15)$ also directly interacted with the 3'UTR region of ER $\alpha$ and regulated ER $\alpha$ expression. Thus, studies have shown critical interactions between ER $\alpha$ and miRNAs and suggested that several miRNAs regulate ER $\alpha$ expression directly or indirectly. It has been shown that the downregulation of miR-342 is associated with ER $\alpha$-negative breast cancer (8) and tamoxifen-resistant breast tumors (16).

The present study was undertaken to assess the expression of miR-342 and ER $\alpha$ mRNA in human breast cancer samples. Correlations between the expression levels of miR-342 and clinicopathological factors were analyzed. For the first time miR-342 expression was identified as positively correlated with ER $\alpha$ mRNA expression. The ectopic expression of miR-342 upregulated ER $\alpha$ mRNA levels and promoted tamoxifen sensitivity in MCF-7 cells, whereas the knockdown of miR-342 reduced ER $\alpha$ mRNA expression and weakened tamoxifen sensitivity. These results indicated that miR-342 may emerge as a significant marker for the tamoxifen response, as well as as a potential therapeutic target.

\section{Materials and methods}

Breast cancer tissues and immunohistochemical analysis. A total of 48 breast cancer cases and 24 normal adjacent tissues from female patients with invasive breast carcinoma, who were treated in the Jiangsu Province Cancer Hospital of China between 2010 and 2012, were included in the present study. The study protocol was approved by the institutional review board and conformed to the guidelines of the 1975 Declaration of Helsinki. All patients had undergone surgical treatment for primary breast cancer (either mastectomy or lumpectomy), without previous chemoradiotherapy and were aged between 31 and 82 years old, with a median age of 48 . The ER $\alpha$, progesterone receptor (PR), human epidermal growth factor receptor 2 (HER2) and vascular endothelial growth factor (VEGF) expression status was confirmed by immunohistochemistry (IHC) as follows. One $4-\mu \mathrm{m}$ section of each submitted paraffin block was first stained with $H \& E$ to verify that an adequate number of invasive carcinoma cells were present and that the fixation quality was adequate for IHC analysis. Serial sections $(4 \mu \mathrm{m})$ were prepared from selected blocks and float mounted onto adhesive-coated glass slides, for staining with monoclonal rabbit anti-human antibodies (Dako, Carpinteria, CA, USA) at a 1:100 dilution. Any brown staining in the invasive breast epithelium was considered a positive result. According to the estimated proportion of tumor cells stained positive, the ER, PR, HER2 and VEGF status was evaluated as follows: Negative $(<10 \%),+(10-30 \%),++(31-50 \%)$ and $+++(>50 \%)$ HER2 gene amplification was analyzed by fluorescence in situ hybridization (FISH) when HER2 status + or ++ , the method has been published elsewhere (17).

Quantitative reverse transcription (RT)-PCR detection of $m i R N A$. Total RNA was extracted from $\sim 500 \mathrm{mg}$ of frozen breast cancer tissue or $\sim 1 \times 10^{6}$ breast cancer cells (MCF-7, SKBR-3,MB-231) using TRIzol reagent (Invitrogen Life Technologies, Carlsbad, CA, USA) according to the manufacturer's instructions. cDNA was reverse transcribed from the total RNA samples using specific miRNA primers from the TaqMan
MicroRNA Assays and reagents from the TaqMan MicroRNA Reverse Transcription kit (Applied Biosystems, Carlsbad, CA, USA). The resulting cDNA was amplified by PCR using TaqMan MicroRNA Assay primers with the TaqMan Universal PCR Master Mix and analyzed with a 7500 ABI PRISM Sequence Detector System according to the manufacturer's instructions (Applied Biosystems). The relative levels of miRNA expression were calculated from the relevant signals by normalization with the signal for U6 miRNA expression. The assay names for miR-342 were hsa-miR-342-3p (Applied Biosystems).

Quantitative RT-PCR detection of $m R N A$. The total RNA $(1 \mu \mathrm{g})$ was subjected to reverse transcription with random primers in a $20-\mu$ l reaction volume using PrimeScript ${ }^{\circledR} \mathrm{RT}$ Master Mix (Applied Takara, Dalian, China). The ER $\alpha$ mRNA expression was measured by quantitative RT-PCR with SYBR Premix Ex Taq ${ }^{\mathrm{TM}}$ (Applied Takara) and primers for ER $\alpha$ (forward, 5'-TGCCCTACTACCTGGAGAAC-3' and reverse, 5'-CCATAGCCATACTTCCCTTGTC-3'), using a 7300 ABI PRISM Sequence Detector System according to the manufacturer's instructions (Applied Biosystems). The relative expression level compared with that of $\beta$-actin was calculated using the comparative $\mathrm{Ct}$ method.

Cell culture and transfections. MCF-7 cells (American Type Culture Collection, Manassas, VA, USA) were grown in DMEM (Gibco, Carlsbad, CA, USA) containing 10\% fetal bovine serum (FBS) and $2 \mathrm{mM} / 1 \mathrm{~L}$-glutamine and penicillin-streptomycin (50 IU/ml and $50 \mathrm{mg} / \mathrm{ml}$, respectively) at $37^{\circ} \mathrm{C}$ with $5 \% \mathrm{CO}_{2}$. The transfection was performed with Lipofectamine $^{\mathrm{TM}} 2000$ Reagent (Invitrogen Life Technologies) according to the manufacturer's instructions. The miR-342-3p mimics, miR-342-3p inhibitor and the negative control (NC) were purchased from Jima Co., Shanghai, China. The concentration of the mimics and inhibitors were 10 and $20 \mathrm{nM}$, respectively. The efficiency of the miR-342 transfection was measured by real-time PCR.

Cell proliferation assay. Following transfection, the MCF-7 cells $(5,000$ cells per well) were plated in 96-well plates and treated with $10 \mathrm{nM}$ 17 $\beta$-estradiol (E2, Sigma, St. Louis, MO, USA) alone or in combination with $20 \mu \mathrm{M}$ tamoxifen (Sigma) for $72 \mathrm{~h}$ subsequent to overnight serum starvation. Cell proliferation was documented using a cell counting kit-8 (CCK-8) assay kit (Dojindo Laboratories, Kumamoto, Japan) and recording absorbance at $450 \mathrm{~nm}$ with a 96-well plate reader.

Apoptosis test. Following transfection, the MCF-7 cells $\left(1.5 \times 10^{5}\right.$ cells per well) were treated with $15 \mu \mathrm{M}$ tamoxifen for $48 \mathrm{~h}$ and then stained with FITC-conjugated anti-Annexin V antibodies. The Annexin V-FITC Apoptosis Detection kit (BD Pharmingen, San Diego, CA, USA) was used to analyze cell apoptosis with flow cytometry (BD Aria; BD Biosciences, Franklin Lakes, NJ, USA).

Statistical analysis. All statistical analyses were performed using SPSS 17.0. All data are expressed as the mean \pm SD of at least 3 independent experiments. The differences between the groups were analyzed using the Student's t-test or ANOVA; $\mathrm{P}<0.05$ was considered to indicate statistically significant results. 
Table I. Correlation between the miR-342 expression level and the clinicopathological characteristics of breast cancer.

\begin{tabular}{|c|c|c|c|}
\hline \multirow[b]{2}{*}{ Variable } & \multirow[b]{2}{*}{$\mathrm{n}$} & \multicolumn{2}{|c|}{$\begin{array}{l}\text { Relative level of } \\
\text { miR-342 }(\log 10)\end{array}$} \\
\hline & & Mean \pm SD & P-value \\
\hline \multicolumn{4}{|l|}{ Age (years) } \\
\hline$\geq 48$ & 16 & $1.202 \pm 0.575$ & 0.935 \\
\hline$<48$ & 32 & $1.215 \pm 0.492$ & \\
\hline \multicolumn{4}{|l|}{ Pathological grade } \\
\hline I, II & 36 & $1.243 \pm 0.560$ & 0.367 \\
\hline III & 12 & $1.116 \pm 0.353$ & \\
\hline \multicolumn{4}{|l|}{ Lymph node status } \\
\hline Metastasis & 32 & $1.218 \pm 0.533$ & 0.893 \\
\hline No metastasis & 16 & $1.197 \pm 0.494$ & \\
\hline \multicolumn{4}{|l|}{ ER } \\
\hline Negative & 14 & $0.785 \pm 0.315$ & 0.000 \\
\hline Positive & 34 & $1.386 \pm 0.480$ & \\
\hline \multicolumn{4}{|l|}{ PR } \\
\hline Negative & 20 & $1.042 \pm 0.531$ & 0.054 \\
\hline Positive & 28 & $1.332 \pm 0.477$ & \\
\hline \multicolumn{4}{|l|}{$\mathrm{HER}{ }^{\mathrm{a}}$} \\
\hline Negative & 20 & $1.482 \pm 0.423$ & 0.001 \\
\hline Positive & 28 & $1.017 \pm 0.492$ & \\
\hline \multicolumn{4}{|l|}{ VEGF } \\
\hline Negative & 18 & $1.416 \pm 0.432$ & 0.031 \\
\hline Positive & 30 & $1.088 \pm 0.528$ & \\
\hline \multicolumn{4}{|l|}{ Molecular Subtype } \\
\hline Luminal A (ER $\left.{ }^{+}, \mathrm{HER}^{-}\right)$ & 16 & $1.624 \pm 0.333$ & 0.000 \\
\hline Luminal B $\left(\mathrm{ER}^{+}, \mathrm{HER}^{+}\right)$ & 18 & $1.175 \pm 0.499$ & \\
\hline $\begin{array}{l}\text { HER2 overexpression } \\
\left(\mathrm{ER}^{-}, \mathrm{HER} 2^{+}\right)\end{array}$ & 10 & $0.732 \pm 0.340$ & \\
\hline $\begin{array}{l}\text { Triple-negative } \\
\left(\mathrm{ER}^{-}, \mathrm{PR}^{-}, \mathrm{HER} 2^{-}\right)\end{array}$ & 4 & $0.918 \pm 0.223$ & \\
\hline \multicolumn{4}{|l|}{ AJCC Clinical Stage } \\
\hline $\mathrm{I}$ & 12 & $1.150 \pm 0.562$ & 0.553 \\
\hline IIA & 30 & $1.193 \pm 0.510$ & \\
\hline IIB $^{b}$ & 6 & $1.423 \pm 0.480$ & \\
\hline
\end{tabular}

aHER2-positive: HER2(+++) or Fish(+). ${ }^{\text {b}}$ There were no patients at clinical stage III or IV in the present study. ER, estrogen receptor; PR, progesterone receptor; HER2, human epidermal growth factor receptor 2; VEGF, vascular endothelial growth factor.

\section{Results}

Correlations between the expression levels of $m i R-342$ and the clinicopathological factors. The expression levels of miR-342 in the 48 human breast cancer tissues were examined. Quantitative RT-PCR detection analysis showed that the expression levels of miR-342 were markedly higher in the ER $\alpha$-positive tumors $(1.386 \pm 0.480)$ than in the ER $\alpha$-negative tumors $(0.785 \pm 0.315 ; \mathrm{P}=0.000)$, that the miR-342 expres-
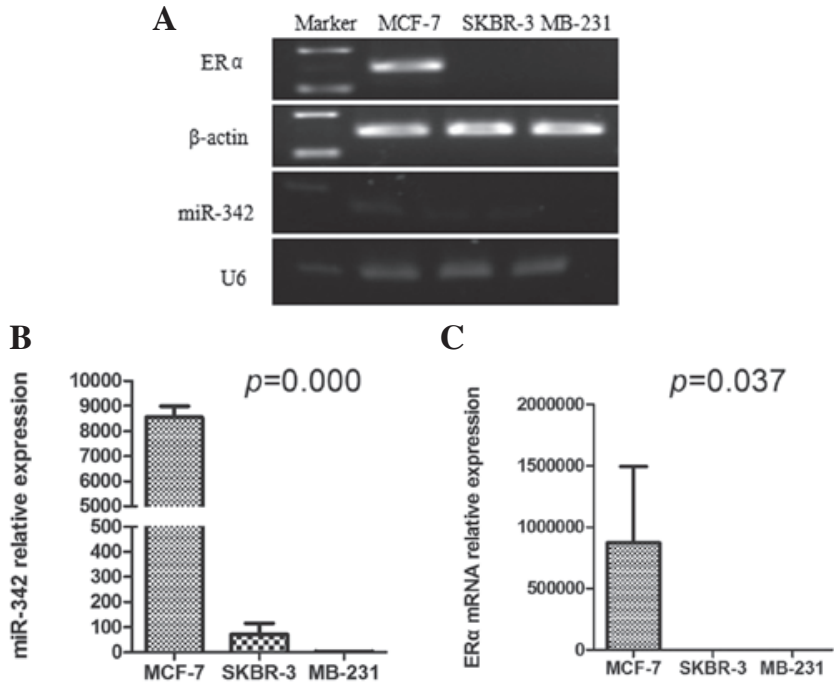

D

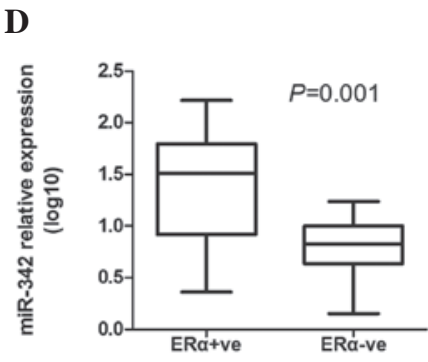

$\mathbf{E}$

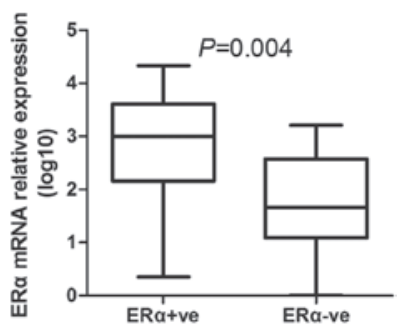

$\mathbf{F}$

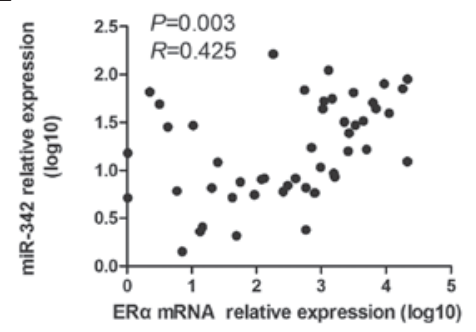

Figure 1. miR-342 is positively correlated with the expression of ERo mRNA in human breast cancer tissues. (A) 3\% agarose electrophoresis of PCR products. Quantitative RT-PCR detection analysis showing that expression levels of (B) miR-342 and (C) ER $\alpha$ mRNA are markedly higher in the ER $\alpha$-positive breast cancer cells (MCF-7) than in the ER $\alpha$-negative cells (SKBR-3 and MB-231). (D) miR-342 and (E) ER $\alpha$ mRNA increased more in the ER $\alpha$-positive tumors than in the ER $\alpha$-negative tumors. (F) Scatterplot shows positive correlation between miR-342 and ER $\alpha$ mRNA expression in the breast cancer tissues. ER $\alpha$, estrogen receptor $\alpha$; mRNA, microRNA; RT-PCR, reverse transcription PCR.

sion levels were increased in the HER2-negative tumors (1.416 \pm 0.432$)$ compared with the HER2-positive tumors $(1.017 \pm 0.492 ; \mathrm{P}=0.001)$ and that $\mathrm{miR}-342$ expression was upregulated in the VEGF-negative tumors $(1.416 \pm 0.432)$ compared with the VEGF-positive tumors $(1.088 \pm 0.528$; $\mathrm{P}=0.031$ ). There was no evident relevance between the levels of miR-342 expression and PR, lymph node metastasis status or the pathological grade $(\mathrm{P}>0.05$; Table I). No discrepancy exists in the miR-342 expression between the cancer $(1.404 \pm 0.529)$ and cancer adjacent $(1.151 \pm 0.387 ; \mathrm{P}=0.065)$ in this study.

miR-342 expression is positively correlated with ER $\alpha$ mRA expression in human breast cancer and cell lines. First the expression levels of ER $\alpha$ mRNA and miR-342 were assessed 

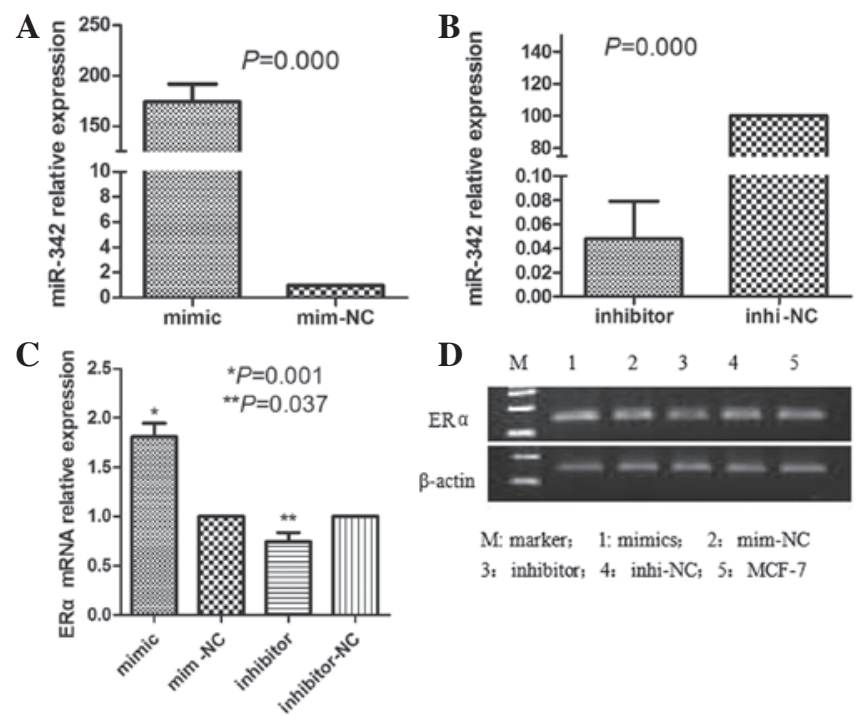

3: inhibitor; 4: inhi-NC; 5: MCF-7

Figure 2. Transfection of miR-342 mimics or inhibitors into estrogen-dependent MCF-7 breast cancer cells changes ER $\alpha$ expression. MCF-7 cells were transfected with either miR-342 mimics (10 nmol/l), inhibitors $(20 \mathrm{nmol} / \mathrm{l})$ or the negative control (NC) and incubated for $48 \mathrm{~h}$ in a medium containing $10 \%$ FBS. The miR-342 levels and ER $\alpha$ mRNA levels were measured by quantitative RT-PCR. (A) miR-342 expression is markedly higher in the cells with the transfection of the miR-342 mimics and lower in the cells with (B) the transfection of the miR-342 inhibitors compared with that of the NC. (C) Quantitative RT-PCR detection analysis and (D) 3\% agarose electrophoresis of PCR products showing that ER $\alpha$ mRNA increased in cells with transfection of the miR-342 mimics and decreased in cells with transfection of the miR-342 inhibitors compared with that of the NC. FBS, fetal bovine serum; miRNA, microRNA; ER $\alpha$, estrogen receptor $\alpha$; RT-PCR, reverse transcription PCR; mim-NC, mimic NC; inhi-NC, inhibitor NC.

in the breast cancer cell lines and the results showed that they were greatly increased in the ER $\alpha$-positive cells (MCF-7) compared with those in the ER $\alpha$-negative cells (SKBR-3 and MB-231; P<0.05; Fig. 1A-C). Next the ER $\alpha$ mRNA and miR-342 expression levels were examined in the human breast cancer tissues. As expected, the expression levels of ER $\alpha$ mRNA were much higher in the ER $\alpha$-positive tumors than in the ER $\alpha$-negative tumors $(2.74 \pm 1.14$ vs. $1.68 \pm 1.02 ; \mathrm{P}=0.004$; Fig. 1E). To analyze the association between the miR-342 expression and the ER $\alpha$ mRNA expression, the expression levels were plotted. The scatterplots showed that miR-342 expression was positively correlated with ER $\alpha$ mRNA expression in human breast cancer $(\mathrm{P}=0.003$; Fig. $1 \mathrm{~F})$.

miR-342 elevates ER mRNA expression of MCF-7 cells and promotes tamoxifen sensitivity. The MCF-7 cells were transfected with the miR-342 mimics at a concentration of $10 \mathrm{nM}$ or with the miR-342 inhibitors at a concentration of $20 \mathrm{nM}$. The control groups were transfected with the miR-342 NCs or with the miR-342 inhibitor NCs. To examine the efficiency of the transfection, total RNA was extracted and the miR-342 level was measured by real-time PCR $48 \mathrm{~h}$ post-transfection. The results showed that the miR-342 expression was significantly increased in the MCF-7 cells following transfection with the miR-342 mimics, when compared with control group treated with the mimic NCs ( $\mathrm{P}=0.000$; Fig. 2A). The miR-342 expression was markedly lower when using the miR-342 inhibitors than when using the miR-342 inhibitor NCs ( $\mathrm{P}=0.000$; Fig. 2B). The ER $\alpha$ mRNA expression was analyzed by RT-PCR,
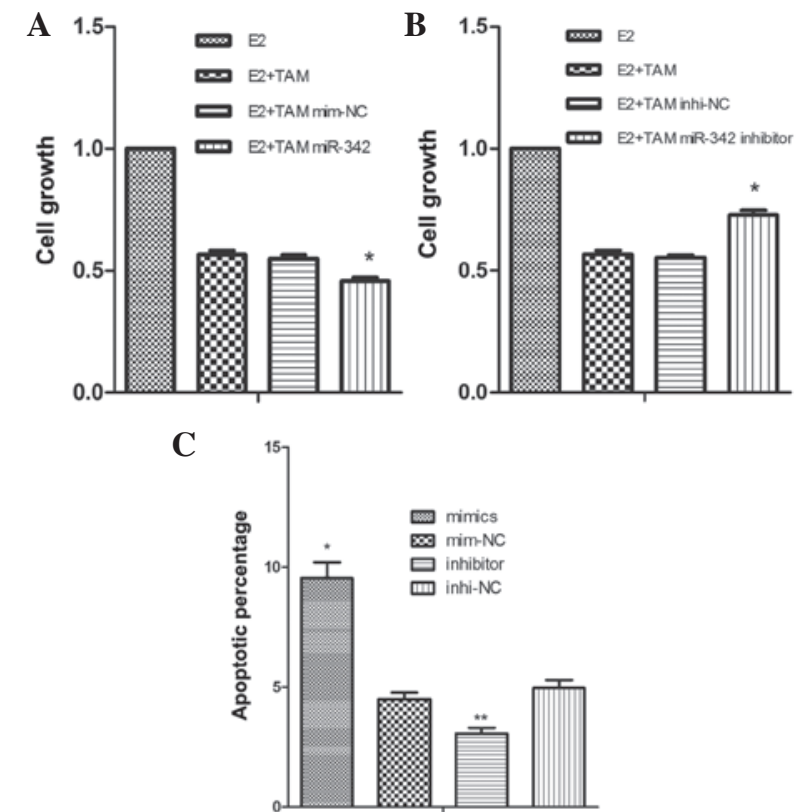

D
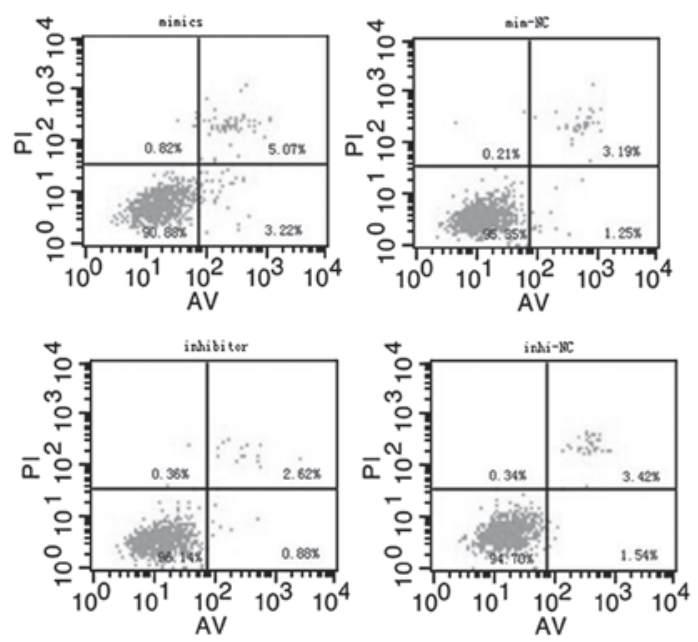

Figure 3. Transfection of miR-342 into MCF-7 cells promotes tamoxifen sensitivity. MCF-7 cells were transfected with either (A) miR-342 mimics (10 nmol/l), (B) inhibitors $(20 \mathrm{nmol} / \mathrm{l})$ or the negative control (NC) and treated the next day with $10 \mathrm{nME} 2$ alone or in combination with $20 \mu \mathrm{M}$ tamoxifen for 72 h. Cell growth was measured by a CCK-8-based cell proliferation assay. Data are presented as mean $\pm \mathrm{SE}$ of three independent experiments relative to $\mathrm{E} 2$ treated MCF-7 cells. Compared with the NC group, (A) * $\mathrm{P}=0.001$; and (B) ${ }^{*} \mathrm{P}=0.000$. (C and D) MCF-7 cells were transfected and treated the next day with $15 \mu \mathrm{M}$ tamoxifen for $48 \mathrm{~h}$ and the apoptosis was quantitated with flow cytometry. (C) Compared with the NC group, ${ }^{*} \mathrm{P}=0.002 ;{ }^{* *} \mathrm{P}=0.011$ mim-NC, mimic NC; inhi-NC, inhibitor NC, TAM, tamoxifen, miR-342, microRNA-342.

which showed that the levels of ER $\alpha$ mRNA expression were upregulated in the group transfected with the miR-342 mimics compared with those in the control group and decreased in the group transfected with the miR-342 inhibitors compared with those in the control group (Fig. 2C and D).

As miR-342 is not differently expressed between the breast cancer and cancer adjacent tissues, we forecast that miR-342 would not play a tumor-suppressive or tumor-promotive role in breast cancer development. To understand the functional role of miR-342, the impact of miR-342 on cellular proliferation was evaluated using CCK- 8 in the MCF-7 cells. The results showed that $96 \mathrm{~h}$ after the use of miR-342 mimics or inhibition 
transfection, the overexpression or suppression of miR-342 was not able to change cellular proliferation. Transfection with the miR-342 mimics compared with the NC, $(2.460 \pm 0.036$ vs. $2.517 \pm 0.050$, respectively; $\mathrm{P}=0.188)$. Transfection with the miR-342 inhibitors compared with the NC, $(2.363 \pm 0.1999$ vs. $2.547 \pm 0.080$, respectively; $\mathrm{P}=0.212)$. However, in the presence of $20 \mu \mathrm{M}$ tamoxifen for $72 \mathrm{~h}$, ectopic miR-342 expression was able to suppress cellular proliferation to a greater extent following transfection with the miR-342 mimics than the cells transfected with the NC $(0.459 \pm 0.013$ vs. $0.55 \pm 0.015$, respectively; $\mathrm{P}=0.001$; Fig. $3 \mathrm{~A}$ ). By contrast, the suppression of miR-342 is able to inhibit cellular proliferation less following the transfection with miR-342 inhibitors than the cells with the NC $(0.729 \pm 0.019$ vs. $0.554 \pm 0.01$, respectively; $\mathrm{P}=0.000$; Fig. 3B).

As tamoxifen is known to induce apoptosis in breast cancer cells (18), the potential role of miR-342 in promoting tamoxifen-mediated apoptosis was explored. For this purpose, miR-342-overexpressing or miR-342-suppressing MCF-7 cells were treated with $15 \mu \mathrm{M}$ tamoxifen for $48 \mathrm{~h}$, then cell apoptosis was analyzed with flow cytometry under the same conditions. The results showed that the apoptotic percentage was higher in the miR-342-overexpressing cells than in the NC (9.54 \pm 1.14 vs. $4.50 \pm 0.46 \%$; $\mathrm{P}=0.002)$. Conversely, the apoptotic percentage was lower in the miR-342-suppressing MCF-7 cells than in the $\mathrm{NC}(3.06 \pm 0.42$ vs. $4.95 \pm 0.59 \%$; $\mathrm{P}=0.011$; Fig. 3C and D). This series of analyses demonstrated that the miR-342 indeed plays a key role in changing the response of MCF-7 cells to tamoxifen.

\section{Discussion}

The present study demonstrated that the expression of miR-342 in the ER $\alpha$-positive breast cancer tumors and cells was significantly greater than that in the ER $\alpha$-negative breast cancer tumors and cells. The study reported for the first time that the levels of miR-342 expression were positively correlated with ER $\alpha$ mRNA expression and also revealed a correlation between increased tamoxifen sensitivity and the elevated levels of ER $\alpha$ mRNA by augmenting the miR-342 expression.

In experimental models, a single miRNA is able to regulate a number of genes (19). It has been reported that miR-22 is downregulated in ER $\alpha$-positive human breast cancer cell lines and clinical samples (13). miR-22 inhibits estrogen signaling by directly targeting the ER $\alpha$ mRA (12). miR-221/222 negatively regulates $\mathrm{ER} \alpha$ and is associated with tamoxifen resistance in breast cancer (14). Previous studies have shown that miR-342 is an ER $\alpha$-associated miRNA (8). The results of the present study show that the expression levels of miR-342 were markedly higher in the ER $\alpha$-positive breast cancer tumors than in the ER $\alpha$-negative tumors and that the levels of miR-342 gradually increased as ER $\alpha$ mRNA expression increased, suggesting that miR-342 is a key factor for the regulation of ER $\alpha$ expression in the development and progression of human breast cancer.

Endocrine therapy has become the most significant treatment option for women with ER $\alpha$-positive breast cancer, with $\sim 70 \%$ of primary breast cancers expressing ER $\alpha$. The selective ER $\alpha$ modulator tamoxifen is the most commonly prescribed endocrine therapy. Currently there are only a few useful tumor markers to guide management decisions for women with ER $\alpha$-positive breast tumors. Cittelly et al (16) demonstrated that miR-342 was markedly suppressed in multiple tamoxifen-resistant breast tumor cell lines and in primary breast tumors of patients whose tamoxifen therapy failed. Significantly, the reintroduction of miR-342 sensitized the refractory breast tumor cells to tamoxifen therapy, suggesting that miR-342 is a significant regulator of the tamoxifen response. In the present study, miR-342 expression was shown to be positively correlated with the expression of ER $\alpha$ in human breast cancer tissues and the introduction of miR-342 into estrogen-dependent breast cancer cells was shown to upregulate ER $\alpha$ expression and enhance tamoxifen sensitivity with decreased cellular proliferation and increased apoptosis. By contrast, inhibition of miR-342 in the MCF-7 cells downregulated the ER $\alpha$ expression and weakened the response to tamoxifen, with increased cellular proliferation and decreased apoptosis. Based on these observations, we propose that the levels of miR-342 expression that correspond to the ER $\alpha$ mRNA expression locus may act as a biomarker for tamoxifen sensitivity in ER $\alpha$-positive breast cancer.

Cittelly et al (16) reported that there was no evident association between the direct targets of miR-342 and the tumor cell response to tamoxifen. Ingenuity Pathway Analysis of the entire set of genes significantly altered by miR-342 revealed a significant association between the miR-342-regulated genes and cell apoptosis. This result is consistent with the observations of the present study that showed that ectopic miR-342 expression sensitized MCF-7 cells to tamoxifen-induced apoptosis. Similarly, miR-342 expression in colorectal cancer cells results in tumor cell apoptosis (20). Nevertheless, the activity of miR-342 appears to differ functionally in colorectal and breast tumor cells. The results of the present study indicated that miR-342 expression alone was not sufficient to induce cell death, but that miR-342 sensitizes cells to cellular proliferation inhibition and apoptosis associated with tamoxifen exposure.

In addition, the results showed that the levels of miR-342 expression increased in VEGF-negative, HER2-negative and Luminal-A breast cancer samples. As the VEGF-negative, HER2-negative and Luminal-A signals indicate a good prognosis, miR-342 may be a biomarker of predicting a good prognosis for breast cancer.

In conclusion, the present data indicated for the first time that miR-342 expression is positively correlated with the expression of ER $\alpha$ mRNA in human breast cancer tissues and that the introduction of miR-342 into estrogen-dependent breast cancer cells enhances tamoxifen sensitivity. miR-342 may be a novel candidate for ER $\alpha$-specific endocrine therapy in breast cancer.

\section{References}

1. Early Breast Cancer Trialists' Collaborative Group (EBCTCG); Davies C, Godwin J, Gray R, et al: Relevance of breast cancer hormone receptors and other factors to the efficacy of adjuvant tamoxifen: patient-level meta-analysis of randomised trials. Lancet 378: 771-784, 2011.

2. Ford CH, Al-Bader M, Al-Ayadhi B and Francis I: Reassessment of estrogen receptor expression in human breast cancer cell lines. Anticancer Res 31: 521-527, 2011.

3. Wiechmann L, Sampson M, Stempel M, et al: Presenting features of breast cancer differ by molecular subtype. Ann Surg Oncol 16: 2705-2710, 2009. 
4. Yamashita H, Ando Y, Nishio M, et al: Immunohistochemical evaluation of hormone receptor status for predicting response to endocrine therapy in metastatic breast cancer. Breast Cancer 13: 74-83, 2006.

5. Krol J, Loedige I and Filipowicz W: The widespread regulation of microRNA biogenesis, function and decay. Nat Rev Genet 11: 597-610, 2010.

6. Esquela-Kerscher A and Slack FJ: Oncomirs - microRNAs with a role in cancer. Nat Rev Cancer 6: 259-269, 2006.

7. Blenkiron C, Goldstein LD, Thorne NP, et al: MicroRNA expression profiling of human breast cancer identifies new markers of tumor subtype. Genome Biol 8: R214, 2007.

8. Lowery AJ, Miller N, Devaney A, et al: MicroRNA signatures predict estrogen receptor, progesterone receptor and HER $2 /$ neu receptor status in breast cancer. Breast Cancer Res 11: R27, 2009.

9. Kondo N, Toyama T, Sugiura H, Fujii Y and Yamashita H: miR-206 Expression is down-regulated in estrogen receptor alpha-positive human breast cancer. Cancer Res 68: 5004-5008, 2008.

10. Adams BD, Furneaux H and White BA: The micro-ribonucleic acid (miRNA) miR-206 targets the human estrogen receptor-alpha (ERalpha) and represses ERalpha messenger RNA and protein expression in breast cancer cell lines. Mol Endocrinol 21: 1132-1147, 2007.

11. Leivonen SK, Mäkelä R, Ostling P, Kohonen P,Haapa-Paananen S, et al: Protein lysate microarray analysis to identify microRNAs regulating estrogen receptor signaling in breast cancer cell lines. Oncogene 28: 3926-3936, 2009.

12. Pandey DP and Picard D: miR-22 inhibits estrogen signaling by directly targeting the estrogen receptor alpha mRNA. Mol Cell Biol 29: 3783-3790, 2009.
13. Xiong J, Yu D, Wei N, Fu H, Cai T, Huang Y, et al: An estrogen receptor alpha suppressor, microRNA-22, is downregulated in estrogen receptor alpha-positive human breast cancer cell lines and clinical samples. FEBS J 277: 1684-1694, 2010.

14. Zhao JJ, Lin J, Yang H, Kong W, He L, Ma X, et al: MicroRNA-221/222 negatively regulates estrogen receptor alpha and is associated with tamoxifen resistance in breast cancer. $\mathrm{J}$ Biol Chem 283: 31079-31086, 2008.

15. Di Leva G, Gasparini P, Piovan C, Ngankeu A, Garofalo M, Taccioli C, et al: MicroRNA cluster 221-222 and estrogen receptor alpha interactions in breast cancer. J Natl Cancer Inst 102: 706-721, 2010.

16. Cittelly DM, Das PM, Spoelstra NS, Edgerton SM, Richer JK, Thor AD and Jones FE: Downregulation of miR-342 is associated with tamoxifen resistant breast tumors. Mol Cancer 9: 317, 2010.

17. Bozzetti C, Nizzoli R, Guazzi A, Flora W, Bassano C, et al: HER2/neu amplification detected by fluorescence in situ hybridization in fine needle aspirates from primary breast cancer. Ann Oncol 13: 1398-1403, 2002.

18. Obrero M, Yu DV, and Shapiro, DJ: Estrogen receptor-dependent and estrogen receptor-independent pathways for tamoxifen and 4-hydroxytamoxifen-induced programmed cell death. J Biol Chem 277: 45695-45703, 2002.

19. Lim LP, Lau NC, Garrett-Engele P, et al: Microarray analysis shows that some microRNAs downregulate large numbers of target mRNAs. Nature 433: 769-773, 2005.

20. Wang H, Wu J, Meng X, et al: MicroRNA-342 inhibits colorectal cancer cell proliferation and invasion by directly targeting DNA methyltransferase 1. Carcinogenesis 32: 1033-1042, 2011. 